


\section{HERMES Spirometry: the European Spirometry Driving Licence}

\section{Introduction}

Spirometry testing is the most widely practiced, most common and adaptable of all lung function tests and spirometers are used as a key instrument in the diagnosis of patients with respiratory disease [1]. As a leading cause of death worldwide responsible for some 9.4 million deaths [2], and further increases predicted by 2020 , the management of lung disease becomes even more dependent on spirometry testing. Yet evidence of widespread under-diagnosis [3] and, as a consequence, reduced quality of life and premature death [4] present cause for concern.

The grim reality evident in the presented studies highlights a real lack of training [5] under-utilisation of spirometers [6] and diagnosis based on inaccurate results [7]. It is reported that chronic obstructive pulmonary disease (COPD), the most prevalent of the lung diseases, is under-diagnosed in $75 \%$ of cases [3]. The outcome of delayed diagnosis deters effective management and treatment, which ultimately aims to relieve symptoms, prevent disease progression, improve health status and prevent premature death [4]. While educational modalities were introduced at a national level to train spirometry practice in some European countries, a survey carried out by the European Respiratory Society (ERS) in 2008 confirms that no formal training in, assessment of, or qualification in spirometry takes place in many other countries. Using the HERMES project framework (Harmonised Education of Respiratory Medicine in European Specialties), a new Spirometry initiative aspires to train and qualify healthcare professionals best able to deliver high-quality spirometry. The potential benefits of standardised educational documents and training in the practice of spirometry are real and significant, strengthening patient care and improving quality of life for respiratory disease patients.

\section{HERMES}

Begun in 2005, the value of the HERMES initiative is that it provides consensus-based standards and indicators to improve quality and practice of education and healthcare, and establishes a guide for teachers and students of sub-speciality respiratory medicine. To date, the Adult HERMES and Paediatric HERMES projects have produced internationally recognised educational documents and activities. If we consider the nature of these projects, it is clear that both the Adult and Paediatric projects appeal to a specific target audience, specialising in precise fields of respiratory medicine. The very essence of the Spirometry HERMES project is, in fact, different. For this purpose, a new proposed structure of four key development areas shall be implemented to ensure all facets of the educational cycle are covered (fig. 1)

\section{Complete Training Programmes}

2. Guidelines for certification of ERS Spirometry Training Programmes

3. Development of educational materials including training manuals, supporting online modules, videos and a knowledge test for part I 4. Assessment guidelines, production of assessments and assessment criteria to test Spirometry Theory and Spirometry Practice

\section{B.G. Cooper (co-chair)}

I. Steenbruggen (co-chair)

S. Mitchell

T. Severin

E. Oostveen

F. Burgos

H. Matthys

H. Normand

J. Kivastik

J. Leuppi

M. Flezar

M. Agnew

0 . Pedersen

S. Sorichter

V. Brusasco

W. Tomalak

P. Palange 


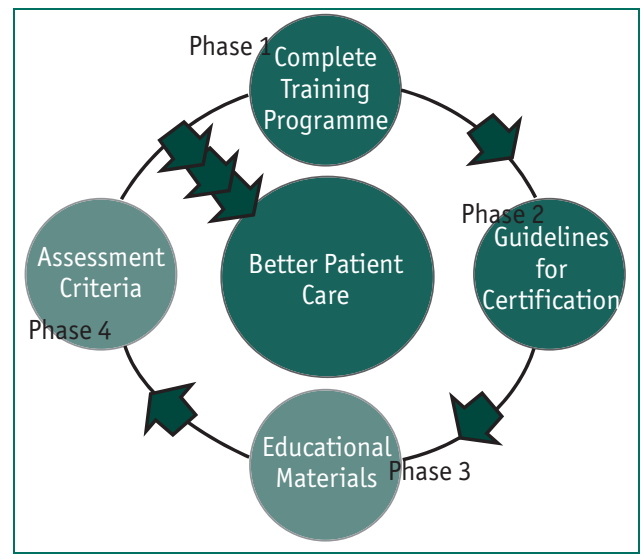

Figure 1

The four key areas of HERMES lead to better patient care.

This process of establishing ERS educational standards in spirometry are international in their development and actively overseen by an expert Task Force representing 13 countries across Europe (fig. 2). The very essence of the HERMES initiative is to offer structured support for educational reform to take place. Evolution of the HERMES ideology presupposes that each project phase recommends uniform educational criteria to be adopted and considered as best practice in training. Considering the statistical data confirming the gravity of lung disease worldwide, the mission of the HERMES spirometry project is to follow this intricate path to train and qualify health professionals to perform

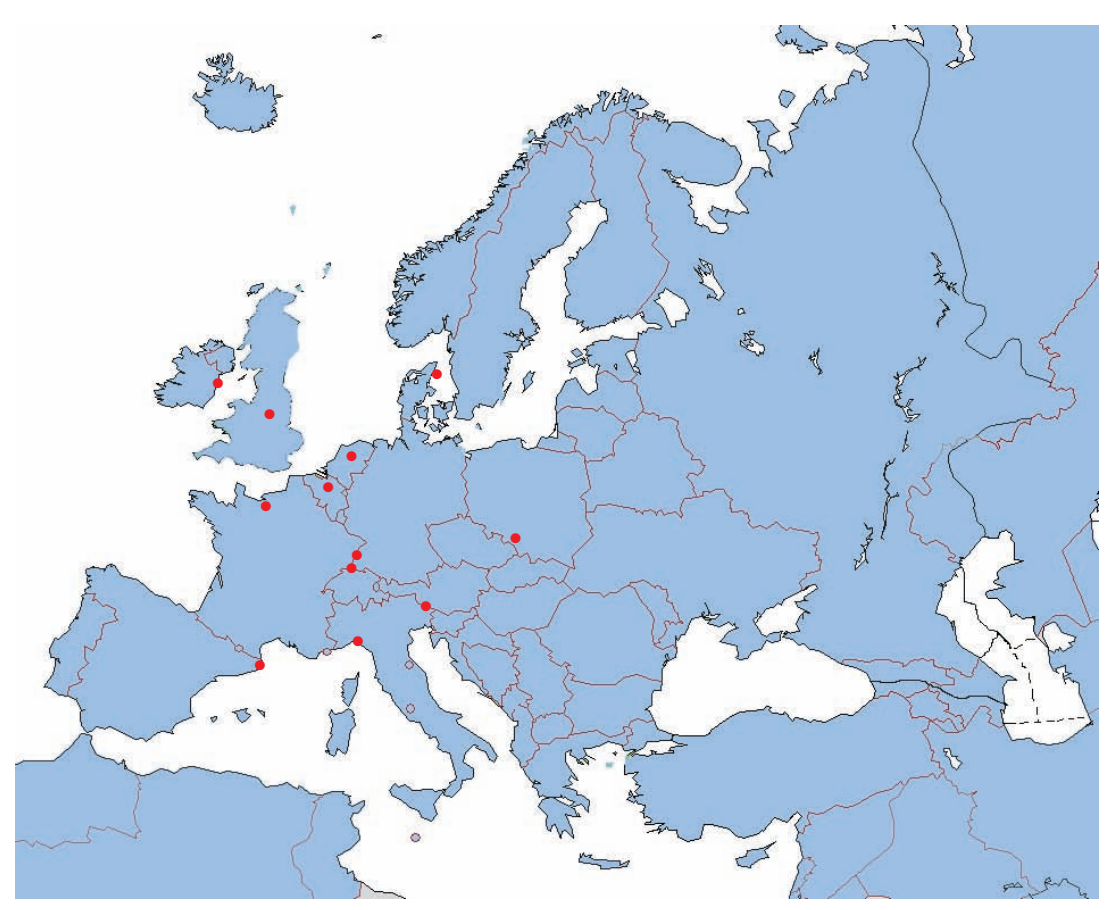

Figure 2 high-quality spirometry tests as well as increasing the number of accurate and repeatable spirometric measurements to be used in the diagnosis of patients with respiratory symptoms. The purpose of this publication is to present the outcome of the first two phases of the HERMES Spirometry Driving Licence project.

\section{Historical background}

Standardisation of spirometry [8], access to spirometers [4] and use of accurate and repeatable spirometry measurements [3] are requirements central to the diagnosis, management and treatment of lung diseases. The scale of the role spirometry plays in identifying patients at risk of disease or of perioperative pulmonary complications such as COPD, lung cancer, heart attack, stroke and asthma [9] dictates that the tools required to practice spirometry be given precedence within the medical arena. The available statistics echo the true reality that spirometers are under-utilised due to absence of teaching practices [6], and there is an extensive call for educational reform in the training of spirometry within this medical domain [1, 3-7, 10].

If the aforementioned requirements to practice quality spirometry are considered, to some extent the ERS/American Thoracic Society 2005 Guidelines in Spirometry Practice and, in recent years, development of the spirometer, guaranteeing widespread distribution, offer some relief to spirometry practitioners. Yet, based on analysis of 14 countries within Europe, only four reported the opportunity to attend a spirometry training course approved by a professional body (fig. 3).

With the intention of producing a driving licence in spirometry for health professionals to reach competency level, the Task Force presents the first of the educational documents; Part I Spirometry Knowledge and Skills, Part II Knowledge and Competence in Spirometry Measurement (leading to the European Spirometry Driving Licence Level II) and Guidelines for the Certification of ERS Spirometry Training Programmes.

\section{Methodology}

The HERMES European Spirometry Driving Licence (ESDL) project was officially launched at the ERS Annual Congress in Berlin 2008 with the aim of harmonising training in spirometry throughout Europe to establish and raise 


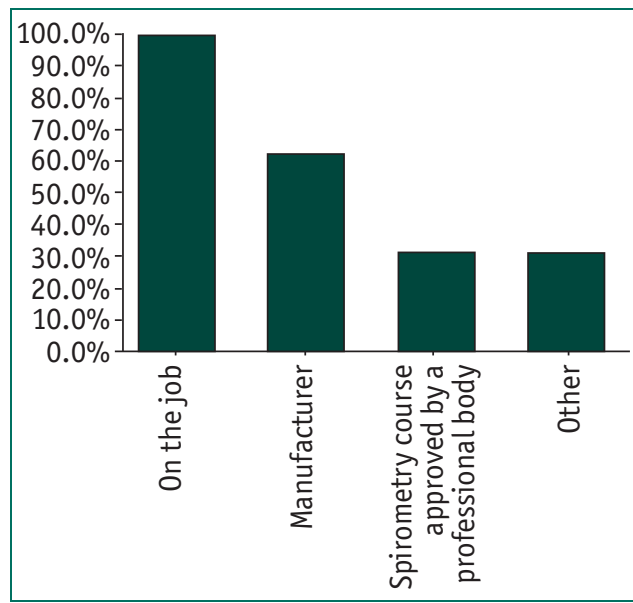

Figure 3

European standards in the skills required to qualify and practice as an expert in this field. Rationale for the project was justified following results of the ERS benchmark analysis carried out in 2008. As well as confirming a clear disconnect in spirometry training practices, insight into expectations of structure, duration, delivery and assessment that a spirometry training programme should possess were offered. Laying the foundations to move forward, the first step the Task Force would take was to produce a training programme outline utilising the well established consensus process, the Delphi technique [11].

\section{Phase 1 - Development of the Training Programme Outline}

Within the framework of the Delphi methodology, and following the steps taken by the HERMES giants, Adult and Paediatric, the Task Force began the process of designing knowledge items which should be included in a training programme for spirometry. A further panel of experts from 10 European countries was also identified as key contributors to project development. In line with the Delphi technique, the Task Force prepared a first survey round and received responses from 673 experts. The aim of this survey was to gather a larger representation from spirometry practitioners of both qualitative and quantitative data on the perceived skills required for training to endorse a qualification in spirometry practice.

At the ERS Annual Congress in 2009 in Vienna, results of the first survey round were presented during a plenary session including all Task Force and national respondents. High consensus levels for each of the items assume that the target of the survey was reached. With the inclusion of some new items and modification of existing items based on comments within the survey, a second Delphi round of 230 experts confirmed the final training programme outline which was approved by the Task Force in May 2010.

As the training programme items were now in place, a new process of developing rationale for training including the course aim, target audience, pre-requisites for training and teaching format would need to be developed. A skeleton structure utilising a number of references $[12,13]$, was presented to the Task Force in May 2010 and so began the final steps in the development of the European Spirometry Driving Licence Training Programme (fig. 4).

\section{Phase 2 - Development guidelines for certification of ERS Spirometry Training Programmes document}

A further output from this landmark May 2010 Task Force meeting was the generation of a number of operational issues relating to the Spirometry Training Programme. Questions sur rounding venue specifications, trainer qualifications and minimum numbers of spirometry tests to be performed, only served to highlight imminent complexities that would need to be addressed.

Between May and the upcoming September 2010 Task Force meeting, the need to stipulate a

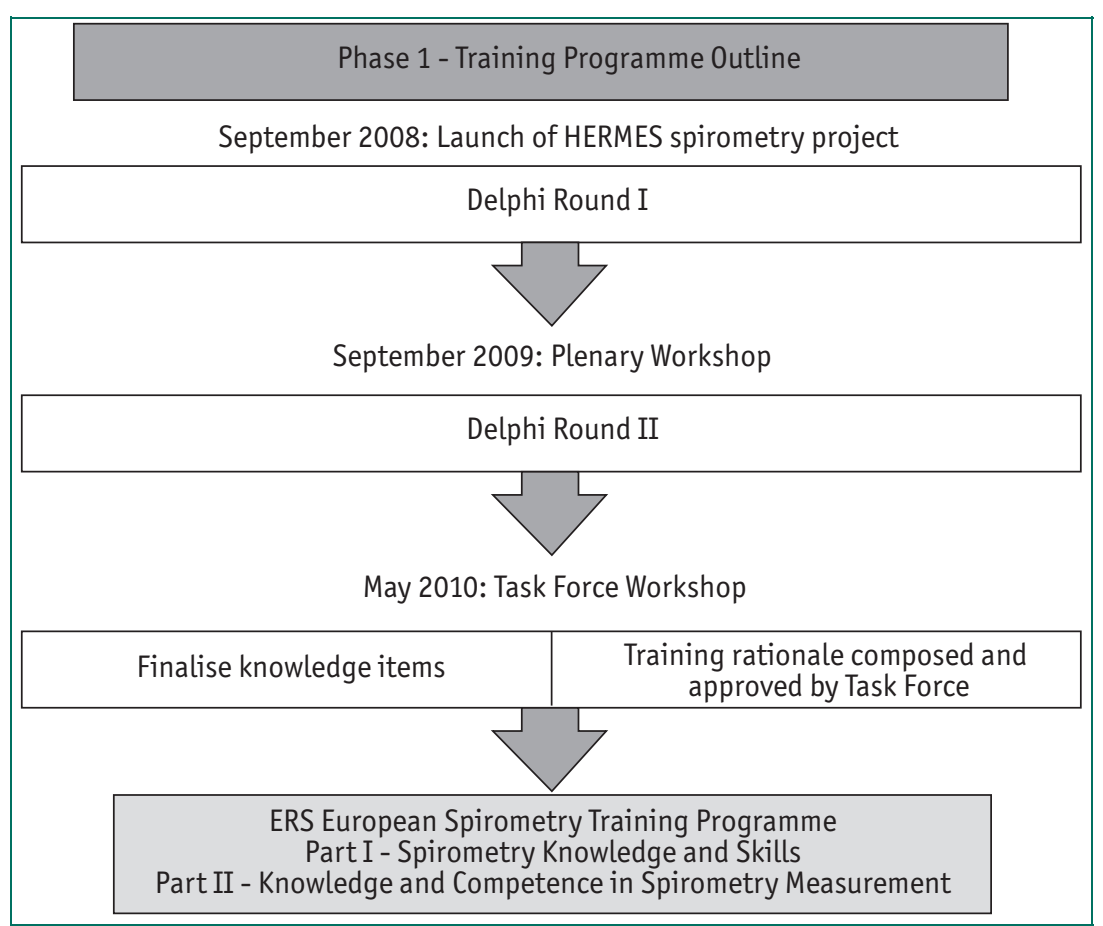

Figure 4

The first phase in the European Spirometry Driving Licence Training Programme. 


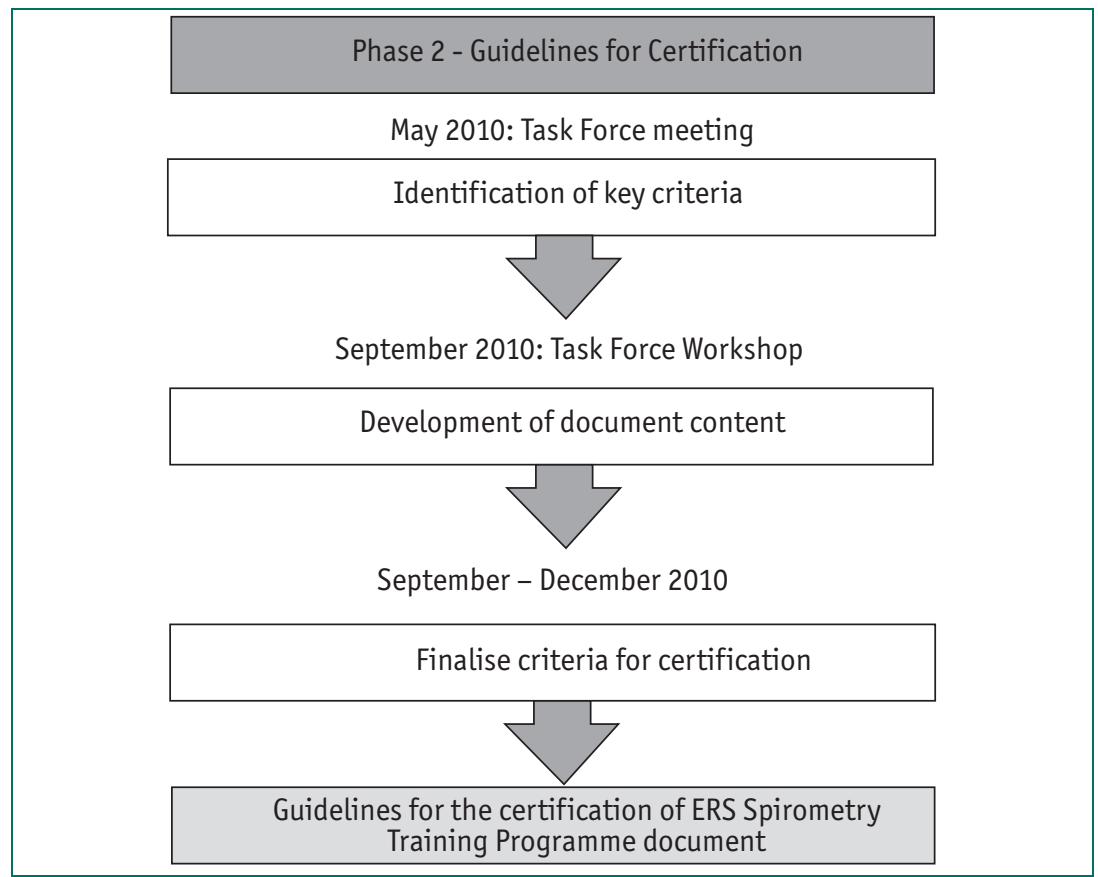

Figure 5

The second phase in the European Spirometry Driving Licence Training Programme.

robust structure including measurable elements and criteria to ensure best practices in training and dissemination of the ESDL became obvious.

Guided by the Criteria for Accreditation of ERS European Training Centres in Adult Respiratory Medicine document generated from the Adult HERMES Task Force [14], the framework provided fundamental standards for training programmes to follow. By September 2010, six sections were presented and approved and the Guidelines for the certification of ERS Spirometry Training Programmes document was established (fig. 5).

\section{Results}

If we consider the objective of the first two project phases to produce a training programme outline and the rationale and guidelines to launch a complete spirometry training programme, the presented documents symbolise the first challenge to lead this initiative toward its end goal, each constituting the minimum recommended criteria that training programmes should consist of for the training of spirometry at a European level.

\section{Phase 1 - Development of the Training Programme Outline}

Drafted by the Task Force during the first of their meetings, 47 knowledge items and skills were presented and included in the first Delphi round. Slight modifications and the addition of new items were made following the first Delphi. Following a second survey round, the training programme was agreed by the Task Force in May 2010, consisting of eight modules and 63 items including prerequisites for training. To ensure all components of an educational training programme were covered, and supported by the ERS education department, further development of the rationale for training was completed by the Task Force during the May meeting.

In order to train practically competent health professionals, it was necessary that the training programme be divided into two distinct training parts:

1. Part I Spirometry Knowledge and Skills covering important spirometry theory and demonstrate best practices in spirometry technique 2. Part II Knowledge and Competence in Spirometry Measurement will ensure participants perfect technique, consider pitfalls and errors in spirometric measurements and award a qualification to merit participants as practically competent to perform high quality spirometry tests

In order to prepare for Part II, the Task Force recognised the need to allow time for practical experience and first hand exposure between training programmes and so have stipulated in the guidelines that all participants must complete the ERS Spirometry Workbook before attending Part II.

Published documents on the complete Training Programme of both Part I Spirometry Knowledge and Skills and Part II Knowledge and Competence in Spirometry Measurement are the result of the first project phase.

\section{Phase 2 - Development guidelines for accreditation of ERS Spirometry Training Programmes document}

The objective of this phase was to generate a structured, simple and flexible model to allow dissemination of training across all health professional settings who practice and teach spirometry across Europe. Utilising specifications within the training programme outline, each of the six sections within the document lists the minimum measurable elements for training programmes to follow to qualify certification 
and award ERS European Spirometry Driving Licence. In September 2010, the document sections were approved and a comprehensive document outlining Guidelines for the certification of ERS Spirometry Training Programmes was completed.

\section{Discussion}

The variety of HERMES initiatives are evolving based on an increasing demand for improved and systematic practices of education in specialist areas of respiratory medicine. Evidence of a current gap in training needs for medical practitioners merely offer conviction to the HERMES Task Forces and remind them of the need to supply this demand. The HERMES spirometry initiative is also the product of this inherent path, emerging from an evident disparity in training criteria in the training of spirometry. Yet producing, implementing and maintaining robust educational activities and documents in specialist medicine are not without challenges.

\section{Challenges}

\section{Application and quality assurance}

Ensuring all healthcare institutions demonstrate the ability to apply predetermined standards set out within the HERMES documents is embedded in complexity. The overarching goal of this project milestone, phase 2 , was to produce a solid foundation of structured guidelines for certification of spirometry training programmes to follow. As the Task Force progresses through the project continuum, a new emphasis moves from documenting minimum criteria to application. In fact, the final section of the Guidelines for certification of ERS Spirometry Training Programmes was established to produce those procedures required for the certification process. For the first time, consideration of the approval body, the application process, the certification process and costs is realised, project success demands a vigorous, adaptable and inexpensive model.

To certify is to apply standards as a basis of quality assurance. Traditionally, accreditation or certification of educational programmes within the medical arena has been based on the wellestablished practice of site visitation [15] However, site visitation is a resource-dependant process, the costs beared by the training centre and, as a consequence, too often excluding those unable to afford external and voluntary certification. The next stages will address this process of certification and it is the intention of the Task Force to publish Section 7 Approval Process and Distribution of ESDL Certificates at a later date which will employ new and diverse methods of quality assurance including preparation of standardised educational materials to be used during training, online training modules, and use of generic assessment methods all contributing as a means of quality control.

\section{Dissemination of the European Spirometry Training Programme} Applying minimum standards not only offers guidance for trainers of spirometry to follow but also present an incentive to improve, or for some countries introduce, structured training and consequently dissemination of a European spirometry qualification. To accomplish success at this project step and indeed looking to future developments for the project, the initiative necessitates distribution to a wide audience of health professionals across a number of medical settings. Consequently, achievement demands educational documents which are simple, robust and adaptable. It is intended that the documents provide a guideline for training programmes of spirometry to follow and to allow flexibility across international, cultural and regional boundaries, which will allow delivery at local level. Support for ESDL trainers will be provided through standardised educational materials as well as a "Train-the-Trainer" course, which will be held each year at the ERS Annual Congress. Moreover, this HERMES project finds itself confronted with the fresh challenge of translation. A new wave of HERMES now looks towards distributing educational documents and activities to national delegates and respondents for translation. Reaching the intended audience requires coherence within ERS and across national societies.

\section{Conclusion}

Spirometry practitioners have the opportunity to take ownership to improve and measure their knowledge and practice of spirometry, emphasising commitment to education and value of attaining a European qualification. For the first time, harmonisation of training in spirometry offers an objective process for evaluation within Europe. With a training programme outline and 
guidelines for certification of ERS training programmes now in place, the Task Force looks to putting theory into practice with a real focus on application. To facilitate a training model, the next project steps intend to design and utilise educational materials, online modules and assessment criteria aligned to concrete standards set out by the Task Force, further strengthening the value of the spirometry HERMES project.

The significance and impact of spirometry as a measure of global health and a predictor of morbidity and mortality resonate throughout the literature [16], and presuppose that spirometry testing receive priority within the medical arena. Yet evidence of a substantial lack of training and inconsistencies in standards across many European countries, there is most certainly scope to improve spirometry practice and reinforce quality patient care. At the core of this impending challenge, the Spirometry HERMES initiative attempts to produce consensus-based documents and guidelines fundamental to the delivery of best practices in spirometry training. It is hoped that project potential will be realised, establishing coherence across national societies, ERS members and all practitioners of spirometry. Building on the shoulders of the previous HERMES projects, with confidence the Spirometry HERMES Task Force takes the first step towards attaining their final mission: delivery of the best possible training to certify spirometry practitioners and improving quality health care for respiratory disease patients.

\section{Acknowledgements}

The following experts participated as national respondents: E. Derom (Belgium), A. Schneider (Germany), R. Pellegrino (Italy), T. Schermer (Netherlands), A. Langhammer (Norway), P. Boros (Poland), H. Hedenström (Sweden), M. Arne (Sweden) and M. Fletcher (UK).

\section{References}

1. Ferguson GT, Enright PL, Buist AS, et al. Office spirometry for lung health assessment in adults: a consensus statement from the National Lung Health Education Program. Chest 2000; 117: 1146-1161.

2. Loddenkemper R, Gibson GJ, Sibille Y. The Burden of Lung Disease, In European Lung White Book: The First Comprehensive Survey on Respiratory Health in Europe. Sheffield, European Respiratory Society/European Lung Foundation, 2003; pp. 2-13.

3. Derom E, Van Weel C, Liistro G, et al. Primary Care Spirometry. Eur Respir J 2008; 31: 197-203.

4. Rabe KF, Hurd S, Anzueto A, et al. Global Strategy for the Diagnosis, Management, and Prevention of Chronic Obstructive Pulmonary Disease GOLD Executive Summary. Am J Respir Crit Care Med 2007; 176: 532-555.

5. Yawn BP, Enright PL, Lemanske RF Jr, et al. Spirometry can be done in family physicians' offices and alters clinical decision in management of Asthma and COPD. Chest 2007; 132: 1162-1168.

6. Bellia V, Pistelli R, Catalano F, et al. Quality control of spirometry in the elderly: The S.A.R.A. study: Salute Respiration nell'Anziano - Respiratory Health in the Elderly. Am J Respir Crit Care Med 2000; 161: 1094-1100.

7. Cleland J, Mackenzie M, Small I, et al. Management of COPD in Primary Care in North-East Scotland. Scott Med J 2006; 51: 10-14.

8. Miller MR, Hankinson J, Brusasco V, et al. Standardisation of spirometry. Eur Respir J 2005; 26: 319-338.

9. Petty TL. John Hutchinson's mysterious machine revisited. Chest 2002; 121: 219S-223S.

10. Townsend M, Hankinson J, Lindesmith L. Is my lung function really that good? Flow type spirometer problems that elevates test results. Chest 2004; 125: 1902-1909.

11. Keeney S, McKenna H. Research guidelines for the Delphi survey technique. J Adv Nurs 2000; 32: 1008-1015.

12. Instructional Methods and the Clinical Learning Setting: An educational guide for the implementation of the Paediatric HERMES curriculum. J0 Busari, et al. in press. 2010 This document is a work in progress and should not be referenced unless and until it is approved and published. Until such time as this Editor's Note is removed, the inclusion of the above document is for informational purposes only.

13. Talbot M. Monkey see, monkey do: a critique of the competency model in graduate medical education. Medical Education 2004; 38: 587-592.

14. R. Loddenkemper, T. Séverin, S. Mitchell, et al. Adult HERMES: criteria for accreditation of ERS European training centres in adult respiratory medicine. Breathe 2010; 7: 170-188.

15. Zach MS, et al. Paediatric respiratory training in Europe: syllabus and centres. Eur Respir J 2002; 20: 1587-1593.

16. Ferguson GT, Enright PL, Buist AS, et al. Office spirometry for lung health assessment in adults: a consensus statement from the national lung health education program. Chest 2000; 117: 1146-1161. 


\section{Successful course participants will be awarded the \\ Level I - European Spirometry Driving Licence}

\section{Course information}

The ERS European Spirometry Training Programme Level I and Level II, is designed to cover all aspects of spirometry that will enable participants to gain sufficient knowledge in spirometry practice and to become high-quality performers of spirometric tests.

Level I of this in training programme is a $9-12$ hour course covering spirometry theory and practice utilising online modules and classroom learning. Participants will only be awarded Level I of the European Spirometry Driving Licence certificate after passing a knowledge based test at the end of the training programme. Level I provides participants with the knowledge and skills to complete an ERS Spirometry workbook and attend Level II training. Participants who successfully complete Level I will acquire knowledge and basic skills but are not yet considered competent in the practice of spirometry.

Before commencing Level II, a number of assignments relating to the practice of spirometry must be completed in the ERS Spirometry workbook. This workbook will form the basis of Level II competency based training and assessment. It is recommended that participants complete Level II training within 6 - 12 calendar months after completing Level I.

Level II of the training is a 7-10 hour training course which will focus on competency - based training and will require participants to complete exercises and submit portfolios of spirometry tests. Examination and the award of the European Spirometry Driving Licence Level II will be dependent on a competency assessment.

\section{Aim of Level I training}

The aim of Level I Spirometry Knowledge and Skills is to ensure that participants acquire the knowledge and basic skills in spirometry best practice. The training programme is designed to cover the theory required to pass the Level I knowledge test and equip participants with the skills needed to perform spirometic tests and successfully complete a Spirometry workbook.

\section{Target audience}

\section{Level I}

Level I of the training programme is aimed at all healthcare professionals who require a comprehensive understanding and the basic skills in spirometry practice.

\section{Pre-requisites for the training programme}

\section{Level I}

The stipulated pre-requisites are outlined below to ensure that participants have the general knowledge and basic computer skills to participate on the European Spirometry Training Programme. It is the responsibility of the participant who will register to attend that they are competent for each of the prerequisites specific to the Level I of the European Spirometry Driving Licence.

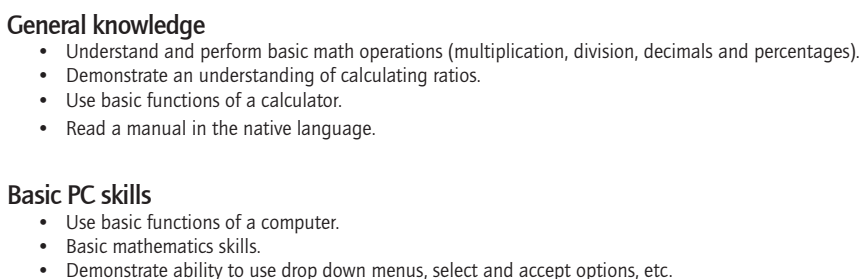

If the training programme requires participants to complete some of the training modules online, then it is mandatory for participants to produce a certificate for each training module completed prior to the course. Participants will not be permitted to sit the knowledge examination unless all modules of the Training Programme are completed.

\section{Course goals}

Participants will gain specific knowledge of the key areas of Spirometry including;

- Anatomy, physiology and pathophysiology of the respiratory system.

The course will also cover the current international standards in spirometry and aims to;

a. provide definitions and explain principles of spirometry.

b. offer an understanding of spirometry systems and reference values and their limitations.

c. present state-of-the-art knowledge on recognising indications and contraindications for spirometry.

d. recognise normal and abnormal spirometry results.

\section{Learning outcomes}

At the end of the training programme, participants will be able to clearly explain and understand each of the key subject areas of spirometry practice including

- definitions of spirometric values.

- knowledge of anatomy, physiology and pathophysiology required for spirometry

- spirometry equipment including strengths and weaknesses, pitfalls and influencing factors to reference values.

- Indications and contraindications of spirometry testing.

- how to perform quality spirometry and recognition of poor quality manoeuvres.

- how to interpret spirometry tests.

- quality assurance, including ability to correctly describe, document, and ensure quality stan dards and practice.

\section{Format}

- Didactic Lectures - Instructional teaching method that allows the student and teacher to effectively understand, consider and analyse the learning goal.

- Small group hands on learning - learning by doing. Practical demonstrations and assessment of technique and interpretation, for example.

- e-Learning Activities - Types of online learning include CD and audio, e-text, forums, threaded discussions, web-blogs, electronic assessments, and simulation learning

- Case-based discussions - Case-based discussion is a structured interview designed to explore professional judgement in specific cases selected by the trainee and presented for evaluation.

- Self Directed Learning - A self-paced process of learning where individuals take initiative, formulate learning goals, and identifies resources for learning.

- Mentoring - Mentoring is a developmental partnership through which one person shares knowledge, skills, information, and perspective to foster the personal and professional growth of someone else. 


\section{Training programme content}

MODULE 1 - ANATOMY, PHYSIOLOGY AND PATHOPHYSIOLOGY REQUI RED FOR SPIROMETRY

- Knowledge of anatomy and physiology of the respiratory system.

- Knowledge of pathophysiology of respiratory disorders.

MODULE 2 - DEFINITIONS OF SPIROMETRIC VALUES

- Explain the principle of spirometry

- Define FEVI, FVC, FEVI/FVC.

- Define PEF, FEF25-75, PIF (NEW ITEM).

- Define VC, IRV, ERV, IC

- Explain the characteristics of a flow-volume curve.

- Explain the characteristics of a volume-time curve.

- Explain the relationship between volume-time and flow-volume curve.

\section{MODULE 3 - SPIROMETRY EQUIPMENT}

- Describe the minimum recommendations for spirometry systems.

- Describe strength and weaknesses of your spirometer

- Recognise pitfalls of the instrument.

- Describe the factors that influence reference values.

MODULE 4 - INDICATIONS AND CONTRAINDICATIONS OF SPIROMETRY TESTING

- Summarise indications and contra-indications for spirometry.

- Summarise the limitations of spirometry.

Note:

Indications can be found in SERIES "ATS/ERS Task Force: Standardisation of Lung Function Testing" Edited by V. Brusasco, R. Crapo and G. Viegi Number 2 in this Series

Standardisation of spirometry

Contra-indications can be found in SERIES "ATS/ERS TASK FORCE: STANDARDISATION OF LUNG FUNCTION TESTING"

Edited by V. Brusasco, R. Crapo and G. Viegi

Number 1 in this Series

General considerations for lung function testing

MODULE 5 - SPIROMETRY TECHNIQUE

- Prepare equipment required for testing

- Demonstrate the correct use of the spirometry device.

- Summarise preparation of subject.

- Describe the correct position to perform spirometry

- Demonstrate height and weight measurement.

- Record type, dosage and time of relevant medication.

- Explain testing procedure to subject.

- Demonstrate the procedure to subject.

- Demonstrate subject coaching.

- Obtain accurate spirometry measurement according to international guidelines (to include examples of international guidelines)

- Recognise improperly performed manoeuvres

- Demonstrate appropriate corrective actions.

- Demonstrate injury prevention knowledge.

- Identify and use standard personal protective equipment

- Demonstrate awareness of confined spaces, including potential hazards, and safety standards.

- Document relevant events that occurred during the spirometric assessment.

- Demonstrate correct method of administering a bronchodilator.

- Summarise issues related to the choice of bronchodilator.

MODULE 6 - QUALITY ASSURANCE

- Describe and perform a control spirometry using a subject with known lung function (biological control).

- Describe and perform calibration or verification check of equipment.

- Describe methods for prevention of infection transmission.

- Explain the rationale for regular cleaning.

- Summarise the requirements for equipment quality control.

- Recognise abnormal traces due to technical or patient errors.

- Describe the advantages of regular over-reading of traces by external experts (samples).

MODULE 7 - EVALUATION OF SPIROMETRIC RESULTS

- Document the acceptability criteria.

- Document the repeatability criteria.

- Document reversibility criteria.

- Summarise test result selection.

- Describe selection of best curve.

- Compare test results with reference values.

- Basic understanding of limitations of reference values.

- Basic understanding of errors of using the percentage predicted and the advantages of using the lower limit of normal.

- Evaluate change in individual subjects.

- Recognise and describe the normal pattern as well as restrictive and obstructive pattern in the volume time curve.

- Recognise and describe the normal pattern as well as restrictive and obstructive pattern in the flow volume curve.

- Knowledge of storage/electronic data.

COURSE ASSIGNMENTS

Understand the next steps to be taken to complete and submit the ERS Spirometry Workbook

including training exercises, portfolio of tests and the assessment process for Level II training

OPTIONAL MODULE

History of Spirometry 


\section{Successful course participants will be awarded the \\ Level II - European Spirometry Driving Licence}

\section{Course Information}

The ERS European Spirometry Training Programme Level I and Level II, is designed to cover all aspects of spirometry that will enable participants to gain sufficient knowledge in spirometry practice and to become high-quality performers of spirometric tests.

Level I of this in training programme is a $9-12$ hour course covering spirometry theory and practice utilising online modules and classroom learning. Participants will only be awarded Level I of the European Spirometry Driving Licence certificate after passing a knowledge based test at the end of the training programme. Level I provides participants with the knowledge and skills to complete an ERS Spirometry workbook and attend Level II training. Participants who successfully complete Level I will acquire knowledge and basic skills but are not yet considered competent in the practice of spirometry.

Before commencing Level II, a number of assignments relating to the practice of spirometry must be completed in the ERS Spirometry workbook. This workbook will form the basis of Level II competency based training and assessment. It is recommended that participants complete Level II training within $6-12$ calendar months after completing Level I.

Level II of the training is a 7 - 10 hour training course which will focus on competency - based training and will require participants to complete exercises and submit portfolios of spirometry tests. Examination and the award of the European Spirometry Driving Licence Level II will be dependent on a competency assessment.

\section{Aim of Level II Training}

The aim of Level II of the training programme is to ensure that participants have acquired the skills and competencies to perform high quality spirometry tests. The training programme will help participants complete a Spirometry workbook, discussing common errors and how to problem solve issues relating to spirometry testing. Level II of the training programme will assist participants with the final preparations to carry out the practical assessment to be awarded the Level II - European Spirometry Driving Licence.

\section{Target Audience}

\section{Level II}

Level II is aimed at all healthcare professionals who wish to become practically competent in the performance of spirometry and who have successfully completed Level I Interactive course on Spirometry and hold the provisional Spirometry Driving Licence.

\section{Pre-requisites for Level II Training Programme}

In order to attend Level II Knowledge and Competence in Spirometry Measurement, participants will be required to present their Level I certification of the European Spirometry Driving Licence.

Practical experience and firsthand exposure are crucial in the learning of spirometric technique to pass Level II and be certified with the ERS European Spirometry Driving License. The number of spirometry tests performed by those participating on the course is not a sufficient measure of competence to practice spirometry. It is mandatory that candidates submit 10 good quality spirometry tests and 5 rejected spirometry tests. Therefore following the successful completion of Level I Spirometry Knowledge and Skills, participants will be required to begin preparations to collect the specified spirometric tests. This information is to be recorded and completed in an Spirometry Workbook and must accompany participants to the Level II Knowledge and Competence in Spirometry Measurement. Participants should be reminded that all clinical details of the subjects as well as tests performed on patients must be anonymous.

\section{Course Goals}

Participants will gain the specific knowledge, skills and competencies required to perform high quality spirometry tests and cover the key areas of Spirometry practice.

Level II Knowledge and Competence in Spirometry Measurement will ensure participants practice spirometry according to current international standards. Following the course participants will;

a. understand the importance of best practice in spirometry service management.

b. correctly perform high quality spirometry and reversibility testing, and fully competent to practice spirometric tests.

\section{Learning Outcomes}

At the end of the training programme, participants will have gained knowledge, skills and

competencies in a number of key areas.

The learning outcomes for Level II of the training course will ensure that participants

- Possess a comprehensive understanding of how to perform quality spirometry and recognition of poorquality manoeuvres.

- Acquire a basic knowledge of how to interpret spirometry tests.

- Perform quality assurance tests, including ability to correctly describe, document, and ensure quality standards and practice.

- Possess the ability to understand, perform and audit spirometry services including equipment maintenance according to international guideline.

\section{Format}

- Didactic Lectures - Instructional teaching method that allows the student and teacher to effectively understand, consider and analyse the learning goal.

- Small group hands on learning - learning by doing. Practical demonstrations and assessment of technique and interpretation, for example.

- e-Learning Activities - Types of online learning include CD and audio, e-text, forums, threaded discussions, web-blogs, electronic assessments, and simulation learning

- Case-based discussions - Case-based discussion is a structured interview designed to explore professional judgement in specific cases selected by the trainee and presented for evaluation.

- Self Directed Learning - A self-paced process of learning where individuals take initiative, formulate learning goals, and identifies resources for learning

- Mentoring - Mentoring is a developmental partnership through which one person shares knowledge, skills, information, and perspective to foster the personal and professional growth of someone else. 


\section{Training programme content}

SPIROMETRY EQUIPMENT (SMALL GROUP HANDS-ON LEARNING)

- Review of workbook assignments.

TECHNIQUE FOR PERFORMING SPIROMETRY (SMALL GROUP HANDS-ON SESSIONS)

Completion of Spirometry workbook to

- Administer spirometric tests.

- Prepare equipment.

- Practice testing technique.

- Recognise pitfalls of spirometry and methods to improve testing technique.

- Recognition of improperly performed manoeuvers etc...

QUALITY ASSURANCE

- Didactic Lectures and use of educational materials and workbooks to.

- Problem -solve issues relating to calibration and verification.

- Calibration and verification check of equipment.

- Recognition of abnormal traces due to technical or patient errors.

EVALUATION OF SPIROMETRIC RESULTS (SMALL GROUP HANDS-ON LEARNING AND CASE-STUDY PRESENTATIONS)

- Use of educational materials and workbooks to evaluate Spirometric Results.

\section{SPIROMETRY SERVICE MANAGEMENT}

- Understands the importance of keeping all results stored safely and accessibility to health care users.

- Performs and records infection control procedures.

- Performs and records quality control procedures.

- Awareness of audit processes and self assessment of the spirometry service to ensure sufficient clinical skills are maintained and quality is upheld.

- Plans and provides consumables for spirometry service (mouthpieces, nose-clips, paper) and ensures routine maintenance of equipment. 


\section{GUIDELINES FOR THE CERTIFICATION OF ERS SPIROMETRY TRAINING PROGRAMMES}
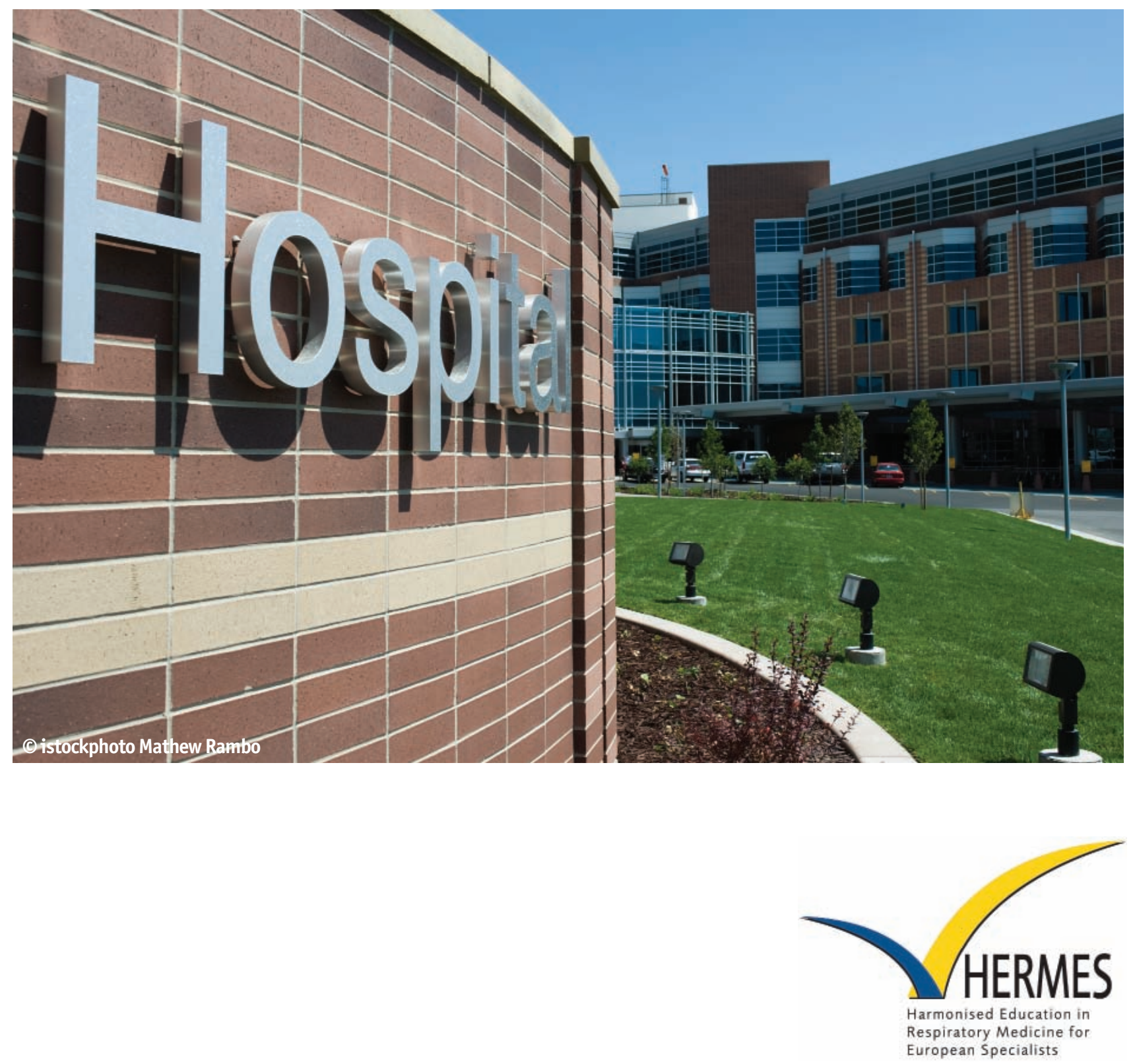


\section{Contents}

Section 1: Minimum Components for training for the ESDL Level I and Level II
a. Duration of Training
b. Optional Training
c. Level I and Level II Training required to be awarded the ESDL

Section 2: Educational Experience
a. Educational Goals
b. Educational Methods
c. Assessment Methods

Section 3: Organisation of the Training Programme
a. Assistant Instructor
b. Course Instructor
c. Course Director

Section 4: Other Organisational Issues
a. Other educational opportunities
b. Minimum numbers of trainees
c. Minimum numbers of training personnel

Section 5: Venue Specifications

a. Space and Equipment

Section 6: Requirements for Specific Facilities
a. Spirometers 


\section{Introduction}

The production of the Guidelines for the certification of ERS Spirometry Training Programme document marks the completion of Phase II of the Spirometry HERMES (Harmonised Education in Respiratory Medicine for European Specialists) project. The project was launched to address disparities in training practices and qualifications in spirometry across Europe. The purpose of this document is to offer training centres a series of recommendations and measurable criteria so those who successfully complete the training programme and assessment have the opportunity to be awarded the European Spirometry Driving Licence Level I and Level II.

This document provides a guideline for best practice for educational directors of spirometry training programmes to follow. To successfully implement an approved spirometry course, a specific process has been established

1. The educational director must complete the HERMES Train-the-Trainer programme at the annual ERS congress

2. An application must be fully completed and submitted for review

3. The application submitted by the educational director may be accepted and the training programme will receive recognition for excellence in spirometry training

During the development of the project, it was decided to divide training into two distinct parts, Level I Spirometry Knowledge and Skills and Level II Knowledge and Competence in Spirometry Measurement, to ensure that participants on the course have the opportunity to reach competency level and complete training workbooks outside of the classroom environment. Therefore, the objective of the project is to ensure that those who complete Level I receive the knowledge and basic skills in Spirometry testing. Only participants who complete Level II of training will be considered fully competent in spirometry measurement. The Guidelines for the certification of ERS Spirometry Training Programme is intended to offer trainers and instructors descriptions of functions and roles as well as other key criteria important to achieve high-quality Spirometry training and certification.

\section{Section 1: Minimum Components for training for the ESDL Level I and Level II}

a. Duration of Training

Duration of training should comply with the specifications recommended within the ERS Euro pean Spirometry Training Programme, 9 - 12 hours day for Level I training and 7-10 hours for Level II training.

A number of training modules for Level I may be completed by the participants online prior to attending the Level I classroom training. Each online module completed by the participants accounts for 1 hour of training time and will reduce classroom training time for Level I.

b. Optional Training

Should the training centre wish to do so, optional modules may also be included in the ERS European Spirometry Training Programme. Optional training modules must take place in addition to the recommended 9-12 hours for Level I and 7-10 hours for Level II of training.

c. Level I and Level II Training

To be awarded the European Spirometry Driving Licence, participants must successfully complete Level I Spirometry Knowledge and Skills and Level II Knowledge and Competence in Spirometry Measurement. 
Level I incorporates the training items (Module 1 - 7) and assessment will fundamentally be based on a knowledge exam after all modules have been covered. It is possible that some mod ules be completed online before the course. If the Training Programme director wishes to incor porate online training, it is their responsibility to ensure that participants produce certification of completion of each online module. Successful participants will be awarded Level I of the European Spirometry Driving Licence.

Level II examines the competence of the individual to put knowledge into practice, and requires participants to submit a completed Spirometry workbook as evidence of their competence in spirometry. Merit to award Level II of the European Spirometry Driving Licence will be decided based on practical assessment and submission of the completed workbook.

Rationale within the Training Programme outline including length of training time, and prerequisites must be adhered to, ensuring that the learning outcomes for participants are reached. It is recommended that participants complete Level II training within 6-12 calandar months after completing Level I.

\section{Section 2: Educational experience}

a. Educational goals

The training programme must allow all those who attend to reach the course goals as outlined in Level I and Level II within the ERS European Spirometry Training Programme Outline

b. Educational Materials

Educational materials including a Spirometry workbook and Training manuals must be used to aid participants to successfully complete both Level I and Level II training.

c. Educational Methods

Specific educational methods have been determined to ensure that every course participant maximise their educational experience on the course. Specific teaching practices for the teach ing faculty to consider include;

i. Didactic Lectures - Instructional teaching method that allows the student and teacher to effectively understand, consider and analyse the learning goal

ii. Small group hands on learning - learning by doing. Practical demonstrations and assess ment of technique and interpretation, for example.

iii. e-Learning Activities - Types of online learning including audio, e-text, forums, threaded dis cussions, web-blogs, electronic assessments, and simulation learning

iv. Case-based discussions - Case-based discussion is a structured intenview designed to explore professional judgement in specific cases selected by the trainee and presented for evaluation

v. Self Directed Learning - A self-paced process of learning where individuals take initiative, formulate learning goals, and identifies resources for learning

vi. Mentoring - Mentoring is a developmental partnership through which one person shares knowledge, skills, information, and perspective to foster the personal and professional growth of someone else.

\section{d. Assessment}

i. The training programme director will be responsible to distribute Level I of the European Spirometry Driving Licence on successful completion of Level I training and assessment.

ii. The training programme director will be responsible to distribute Level II of the European Spirometry Driving Licence certificate to those who successfully complete training and assessment for Level II within 6-12 calandar months after completing Level I assessment.

iii. The teaching faculty should encourage trainees to continue to learn and gain sufficient knowledge and experience

iv. Assessment of the ERS ESDL should follow specific assessment criteria for Level I training 
Level l:

Objective: To determine if a course participant has sufficiently gained the knowledge and basic skills of spirometry in practice

Assessment: All candidates will be requested to pass a knowledge examination estab lished by ERS.

V. Assessment of the ERS ESDL should follow specific assessment criteria for Level II training Level II:

Objective: To determine if a course participant has gained sufficient competence in spirometry measurement.

Assessment: The assessments outlined below as mandatory assessment techniques must be utilised in the assessment of candidates to successfully be awarded Level II of the European Spirometry Driving Licence. A number of desirable assessment techniques are also listed however these are not essential to the assessment of Level II

vi. Assessment of Level II may be carried out locally by the entire training faculty under the direct supervision of the Training Programme director

vii. Level II training must assess all core modules outlined within the Training Programme Out line for Level II and within the assessment guidelines document. Assessment must apply the mandatory assessment methods.

Mandatory Assessment Methods

1. Practical test - knowledge and skills must be demonstrated by the participant before issuance of Level II of the European Spirometry Driving Licence certificate. The examiner may conduct the practical test in any sequence that will result in a complete and efficient test

2. Following successful completion of Level I, if participants wish to attend Level II, the training centre must request that all course participants submit a completed Spirometry Workbook, including 10 good quality tests and 5 rejected spirometry tests, which is to be signed off by the course director/course instructor

Desirable Assessment Methods

1. Case-based discussions

\section{Section 3: Organisation of the Training Programme}

This section describes the roles and functions in the organisation of the ERS Spirometry Training Programme, important to achieve high quality training. Although the structure is intended to give some flexibility across countries applying for accreditation, the minimium specifications outlined within the document should be adhered to. Responsibilities can be attributed to a single position depending on the size and structure of the local programme.

To apply for accreditation and in order to distribute both Level I Spirometry Knowledge and Skills and Level II Knowledge and Competence in Spirometry Measurement, the training programme must be supervised by a course director who has the authority and qualifications to oversee the entire training programme. Depending on the size of the programme, the following specifications determine a teaching member's participation: 
Roles and Trainer Specifications

a. Course Director

Qualifications should ideally include;

1. Certified degree in respiratory physiology or a related field

2. Extensive experience in procedures and instrumentation for spirometry testing

3. Experience in interpretation of spirometry

4. At least 5 years experience in the supervision of a pulmonary function laboratory

5. It is mandatory that the programme director has attended the HERMES Train-the-Trainer

Responsibilities include;

1 To ensure that all those who participate in instruction and teaching on the training pro gramme are sufficiently qualified to do so

2 To ensure that the course outline and structure are consistent with the guidelines provided by the European Respiratory Society

3 To ensure that the teaching material is up to date, relevant and in accordance with the ESDL curriculum.

4 To provide a respiratory clinician/pulmonologists to input into the design and delivery of the course locally.

b. Course Instructor

Qualifications should ideally include;

1. Certified degree in pulmonary physiology or a related field

2. Commitment to keeping up to date

3. It is recommended that the course instructor has attended the HERMES Trainer-the-Trainer

4. Strong teaching/training background in best practices of spirometry testing

Responsibilities include;

1. Oversee progress of mentoring the trainees and offer support throughout the training pro gramme

2. To teach the course content according to the specifications within the training guide

3. Provide feedback on assessment

4. Must have in depth knowledge of spirometry testing and offer knowledge of the key areas of Spirometry as outlined in the Training Programme

5. To organise the administration of the course and to ensure a suitable venue, with appropriate audio-visual facilities and acceptable level of tutor:student ratios

Note: Depending on the size and structure of the training programme, the course director and course instructor roles maybe shouldered by one and the same person.

c. Assistant Instructor

Qualifications ideally should include;

1. Strong interest in the education and best practices of spirometry testing

2. At least some experience in the background, training, and practical aspects of collecting spirometry data and quality control

3. It is mandatory that the assistant instructor has obtained the European Spirometry Driving Licence

Responsibilities ideally include;

1. To assist the course director and course instructor with instructional methods throughout the training programme

2. Responsible for small group hands on sessions during the programme offering demonstrations and 'how to' knowledge of high-quality spirometry testing

3. Coaching of participants 


\section{Section 4: Other organisational issues}

a. Minimum numbers of training personnel

i. The training centre must ensure that the student: teacher ratio is sufficient to maximise learning and that the educational goals are met as outlined in the ERS European Training Programme Outline

For theoretical training, the recommended student: teacher ratio is up to 30:1

For practical training, the recommended student: teacher ratio up to 5:1

b. Other educational opportunities

i. Where necessary, the training faculty must provide other educational activities such as to assist participants find a suitable mentor, be available to answer questions or coach stu dents outside classroom time.

\section{Section 5: Venue specifications}

This section describes the facilities required to ensure that all participants gain adequate experience and exposure to meet the programme objectives and comply with the guidelines provided by ERS.

a. Space and Equipment

There must be adequate space and equipment to cope with the requirements of the content of the programme, including the necessary number of meeting rooms with tables and elec trical equipment, AV facilities, breakout rooms, educational aids as well as electrical sockets for spirometers.

\section{Section 6: Requirements for Specific Facilities}

The training centre must provide all facilities necessary to ensure adequate exposure to demonstrations and hands-on learning of spirometric techniques

a. Use of Spirometers

i. The recommended minimum number of spirometers to be used during training is 1 spirom eter to every 5 students

ii. All participants on the course should be encouraged to bring their own spirometers to the course

iii. Spirometers must meet the ATS/ERS requirements outlined in Standardisation of Spirometry [1] 